\title{
Changes in North American Atmospheric Circulation and Extreme Weather: Influence of Arctic Amplification and Northern Hemisphere Snow Coverd
}

\author{
STEPHEN J. VAVRUS AND FUYAO WANG \\ Nelson Institute Center for Climatic Research, University of Wisconsin-Madison, Madison, Wisconsin \\ JONATHAN E. MARTIN \\ Department of Atmospheric and Oceanic Sciences, University of Wisconsin-Madison, Madison, Wisconsin \\ JENNIFER A. FRANCIS \\ Department of Marine and Coastal Studies, Rutgers, The State University of New Jersey, New Brunswick, New Jersey \\ YANNICK PEINGS \\ Department of Earth Systems Science, University of California, Irvine, Irvine, California \\ JULIEN CATTIAUX \\ Centre National de Recherches Météorologiques, UMR 3589 CNRS/Meteo-France, Toulouse, France
}

(Manuscript received 21 October 2016, in final form 17 February 2017)

\begin{abstract}
This study tests the hypothesis that Arctic amplification (AA) of global warming remotely affects midlatitudes by promoting a weaker, wavier atmospheric circulation conducive to extreme weather. The investigation is based on the late twenty-first century over greater North America $\left(20^{\circ}-90^{\circ} \mathrm{N}, 50^{\circ}-160^{\circ} \mathrm{W}\right)$ using 40 simulations from the Community Earth System Model Large Ensemble, spanning 1920-2100. AA is found to promote regionally varying ridging aloft $(500 \mathrm{hPa})$ with strong seasonal differences reflecting the location of the strongest surface thermal forcing. During winter, maximum increases in future geopotential heights are centered over the Arctic Ocean, in conjunction with sea ice loss, but minimum height increases (troughing) occur to the south, over the continental United States. During summer the location of maximum height inflation shifts equatorward, forming an annular band across mid-to-high latitudes of the entire Northern Hemisphere. This band spans the continents, whose enhanced surface heating is aided by antecedent snow-cover loss and reduced terrestrial heat capacity. Through the thermal wind relationship, midtropospheric winds weaken on the equatorward flank of both seasonal ridging anomalies - mainly over Canada during winter and even more over the continental United States during summer-but strengthen elsewhere to form a dipole anomaly pattern in each season. Changes in circulation waviness, expressed as sinuosity, are inversely correlated with changes in zonal wind speed at nearly all latitudes, both in the projections and as observed during recent decades. Over the central United States during summer, the weaker and wavier flow promotes drying and enhanced heating, thus favoring more intense summer weather.
\end{abstract}

\section{Introduction}

Numerous studies have suggested a relationship between midlatitude weather and Arctic amplification (AA) of global climate change (e.g., Newson 1973;

Supplemental information related to this paper is available at the Journals Online website: http://dx.doi.org/10.1175/JCLI-D-16-0762.s1.

Corresponding author e-mail: Stephen Vavrus, sjvavrus@wisc.edu
Honda et al. 2009; Petoukhov and Semenov 2010; Liu et al. 2012; Cohen et al. 2014; Coumou et al. 2015). Francis and Vavrus (2012, hereinafter FV12) and Overland et al. (2015) described a proposed chain of causality, linking AA to a reduced meridional geopotential height gradient aloft, which leads to weaker upper-air extratropical westerlies, a wavier circulation, and the promotion of more frequent and persistent circulation patterns that favor extreme weather. Empirical evidence demonstrates a strong relationship between 
extreme weather events and slow-moving, high-amplitude wave patterns (Thompson and Wallace 2001; Meehl and Tebaldi 2004; Petoukhov et al. 2013; Screen and Simmonds 2014), but whether AA actually forces such remote circulation changes remains in question (Vihma 2014; Walsh 2014; Cohen et al. 2014). Moreover, this hypothesized correlation is complicated by recent studies showing that expressions of Arctic-midlatitude teleconnections are probably regionally dependent (Overland et al. 2015; Kug et al. 2015). Furthermore, while the connection between a reduced meridional pressure gradient and a weaker zonal wind stems directly from thermal wind considerations, the subsequent linkage between a weaker zonal wind promoting enhanced meridional flow is harder to establish. In part this difficulty arises because different metrics have been used to quantify waviness, which has led to varying conclusions about recent trends in blocking and other high-amplitude patterns (Screen and Simmonds 2013; Barnes et al. 2014; Kennedy et al. 2016; Francis and Vavrus 2015, hereinafter FV15).

The purpose of this study is to test the FV12 hypothesis under very strong greenhouse forcing, over a single geographic domain, and using multiple model realizations to improve the signal-to-noise ratio, which is relatively weak in observational studies that span only the recent short period of enhanced Arctic warming (since the mid-to-late 1990s). We focus on the projected late twenty-first-century climate change over greater North America $\left(20^{\circ}-90^{\circ} \mathrm{N}\right.$, $50^{\circ}-160^{\circ} \mathrm{W}$ ) using 40 realizations from the Community Earth System Model Large Ensemble (LENS; Kay et al. 2015). For comparison, we also analyze observed trends using the NCEP-NCAR Reanalysis-1 (NNR; Kalnay et al. 1996) from 1948 to 2014 . A similar methodology has recently been applied to analyze the strength and waviness of the midlatitude circulation on a hemispheric scale using LENS Peings et al. 2017, manuscript submitted to J. Climate, hereinafter PCVM), reanalyses (Di Capua and Coumou 2016), and a combination of data from reanalyses and phase 5 of the Coupled Model Intercomparison Project (CMIP5; Cattiaux et al. 2016). All of these studies identified changes in midlatitude circulation that varied seasonally and regionally, but their focus was not exclusively North America. In addition, their reference location for representing the extratropics was fixed at a single latitude, which is a useful approach for succinctly characterizing aggregate circulation but potentially limiting in capturing variations within geographic sectors. A similar regionally averaged perspective using CMIP5 output was provided by Barnes and Polvani (2015), who described projected midlatitude circulation changes over the North America-Atlantic region based on the average response from $30^{\circ}$ to $70^{\circ} \mathrm{N}$.
In this study, we extend these prior findings by revealing a more complete spatial picture of greenhouseforced climate changes within the North American region. As in prior studies, our analysis considers changes in both the speed and waviness of the atmospheric circulation and their implications for extreme weather. Following Cattiaux et al. (2016) and PCVM), we quantify waviness using the metric of sinuosity (SIN), a common metric in geomorphology to measure the waviness of streams that was described by J. E. Martin et al. (2017, unpublished manuscript, hereinafter MVWF) as a way to characterize midtropospheric atmospheric circulation. Di Capua and Coumou (2016) employed a similar metric called the meandering index $M$. Strongly zonal flow patterns result in low values of SIN and $M$, whereas very meridional patterns yield high SIN and M. Based on the FV12 hypothesis, we expect that Arctic amplification will contribute to a weaker and more sinuous circulation in midlatitudes.

Here we extend these related recent studies by presenting SIN as a function of latitude to identify potentially distinct responses in the behavior of the circulation across the vast expanse of the extratropics $\left(20^{\circ}-90^{\circ} \mathrm{N}\right)$ over greater North America. Rather than considering the entire Northern Hemisphere, we adopt a regional focus for several reasons. First, shrinking the domain reduces the risk of diluting the signal when combining sectors whose flow becomes more zonal with sectors trending toward more meridional circulation. Second, extreme weather has been increasing in recent years over this region, based on the U.S. climate extremes index (Gleason et al. 2008), featuring many high-profile events such as Superstorm Sandy in 2012 and the socalled polar vortex in 2014. Third, this region experiences the clearest dipole pattern of projected future changes in zonal winds aloft and thus serves as a useful test bed for the expected relationship between waviness and circulation strength. Fourth, the North American domain encompasses a distinct climatological ridgetrough couplet from west to east (Singh et al. 2016), providing a clearly defined wave structure for computing sinuosity. Fifth, recent research has found a strong regional dependence on the teleconnections between Arctic change and midlatitude weather (e.g., Overland et al. 2015 and references therein).

\section{Data and methods}

We utilize $500-\mathrm{hPa}$ daily geopotential heights and zonal wind speeds from both atmospheric reanalysis and global climate model simulations. The reanalysis data are from NNR (Kalnay et al. 1996), with horizontal resolution of $2.5^{\circ} \times 2.5^{\circ}$ and spanning 1948-2014. Similar results are obtained using data from the 40-yr 

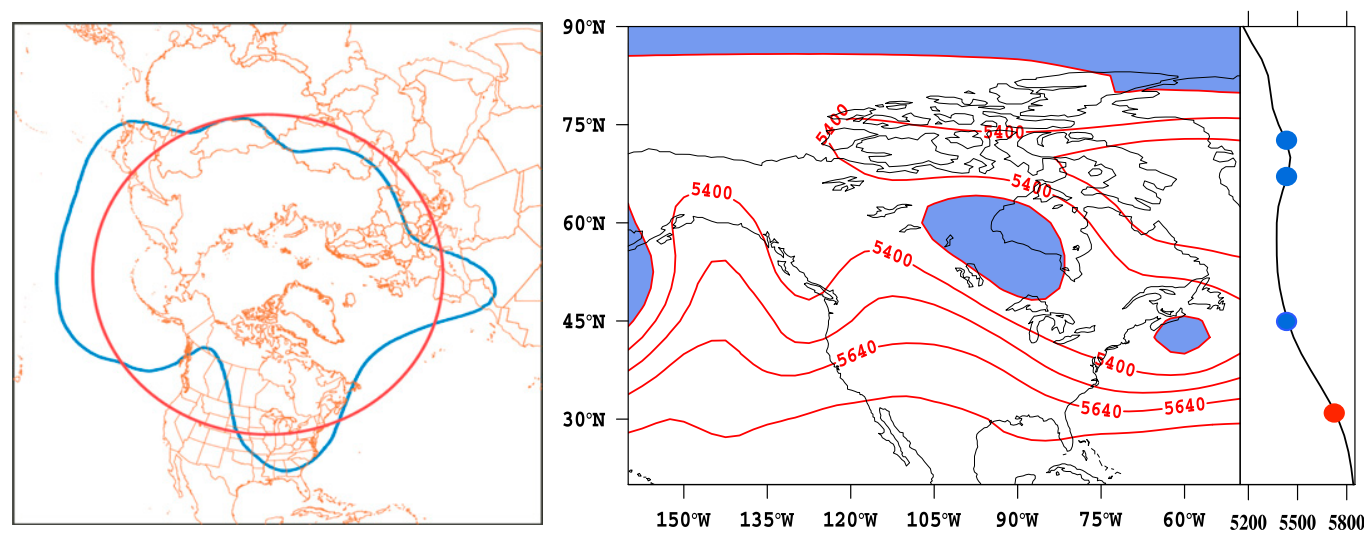

FIG. 1. Example of sinuosity calculations for simple hemispheric and complex regional cases. (left) Blue line is a geopotential height contour at $500 \mathrm{hPa}$. The area enclosed poleward of that contour is equal to the area within the red circle, the equivalent latitude. Sinuosity equals the ratio of the length of the blue curve to the length of the red circle. (right) Example of regional sinuosity in a flow with multiple features. Using the most complex case of the 5280-m isohypse as an example, sinuosity is based on the combined length of all 5280-m isohypse segments bounding the blue shading. This sum is divided by the arclength of the equivalent latitude determined by the sum of all shaded areas. See text for additional explanation.

European Centre for Medium-Range Weather Forecasts (ECMWF) Re-Analysis (ERA-40) data and ERAInterim, so only the findings from NNR are shown here. The simulated atmospheric data from both historical and projected [representative concentration pathway 8.5 (RCP8.5)] LENS simulations are from the Community Earth System Model, version 1 (Community Atmosphere Model, version 5) [CESM1(CAM5)], which produces one of the most realistic climatologies in the CMIP5 suite of models (Knutti et al. 2013). Furthermore, the projected changes in upper-air circulation in LENS closely resemble the average CMIP5 pattern, suggesting that the findings identified here are representative. Each of the 40 ensemble members within LENS uses historical radiative forcing from 1920 to 2005 and RCP8.5 radiative forcing thereafter until 2100. Each model realization differs from one another by only small round-off level variations in their atmospheric initial conditions. The CESM1(CAM5) version used here is the $1^{\circ}$ latitude-longitude configuration $(0.9 \times 1.25$ gx $1 \mathrm{v} 6)$. The large size of the ensemble helps to distinguish signals of change from internal noise.

The strength of the circulation is defined as the speed of the zonal wind aloft, taken at a standard midtropospheric reference level of $500 \mathrm{hPa}$, while the more challenging description of circulation waviness is achieved through the SIN metric. As described in Cattiaux et al. (2016), SIN is defined as the ratio of the curvilinear length of a 500-hPa geopotential height contour (isohypse) to the perimeter of its equivalent latitude, where the contour and the equivalent latitude enclose the same area within the regional boundaries (Fig. 1). Relating its usage here to the more common application of sinuosity in geomorphology, the length of an isohypse is analogous to the length of a stream, while the perimeter of its equivalent latitude is akin to the shortest distance between the starting and ending points of that stream. SIN thus quantifies atmospheric waviness by representing the departure of $500-\mathrm{hPa}$ height contours (isohypses) from a purely zonal orientation, and it accounts for closed circulation systems such as blocking highs and cutoff lows.

As noted in MVWF, other metrics have also been used to characterize the waviness of the large-scale circulation, such as the zonal index (Rossby et al. 1939), the circularity ratio (Rohli et al. 2005), high-amplitude wave frequency (FV15), effective diffusivity (Nakamura 1996), meandering index (Di Capua and Coumou 2016), and various versions of wave activity (Nakamura and Solomon 2010; Huang and Nakamura 2016; Chen et al. 2015). Although each of these measures provides particular insights into the waviness of the flow, sinuosity applied to large-scale geopotential height fields offers an attractively intuitive description of the circulation compared with related metrics.

To create a single value of SIN that characterizes waviness in midlatitudes, we follow MVWF by computing an aggregate sinuosity (ASIN) as a weighted average by using a set of five 500-hPa isohypses $(576,564,552,540$, and 528 dam) representative of the midlatitude circulation:

$$
\operatorname{ASIN}=\frac{\left(L_{576}+L_{564}+L_{552}+L_{540}+L_{528}\right)}{\left(\mathrm{EL}_{576}+\mathrm{EL}_{564}+\mathrm{EL}_{552}+\mathrm{EL}_{540}+\mathrm{EL}_{528}\right)},
$$

where $L$ represents the length and EL the equivalent length of the isohypse within the greater North American 
domain. By boiling down the entire regional circulation into a single index, the purpose of aggregate sinuosity is similar to that of Cattiaux et al. (2016) and PCVM), who represented the whole midlatitude circulation from $30^{\circ}$ to $70^{\circ} \mathrm{N}$ by calculating SIN at the approximate midpoint $\left(\sim 50^{\circ} \mathrm{N}\right)$. Likewise, Di Capua and Coumou (2016) applied their meandering index to the latitude of maximum daily waviness, around $60^{\circ} \mathrm{N}$, but their index does not account for closed circulation features.

To obtain more information on the spatial variations of waviness within the domain, we also apply a more comprehensive method by expressing SIN as a function of latitude rather than particular geopotential heights. We first calculate daily SIN for individual geopotential height contours from 4600 to $6050 \mathrm{~m}$ in $10-\mathrm{m}$ increments to obtain a quasi-continuous magnitude of sinuosity across a span of geopotential heights characteristic of the extratropics. This geopotential height range covers all values in both the historical and future climates. The second step is to compute the zonally averaged geopotential height across each latitude band on every day, as illustrated in Fig. 1, right. We then assign to each latitude the SIN corresponding to the height contour representing that latitude. For example, the zonally averaged height at $30^{\circ} \mathrm{N}$ is $5730 \mathrm{~m}$ (red dot in Fig. 1), and thus $30^{\circ} \mathrm{N}$ is assigned the sinuosity of the $5730-\mathrm{m}$ isohypse. If a zonally averaged height occurs at more than one latitude, then the SIN at each of these latitudes is identical, as shown for the 5430-m isohypse, whose sinuosity is assigned to $45^{\circ}, 67^{\circ}$, and $73^{\circ} \mathrm{N}$ (blue dots). Expressing SIN as a function of latitude accounts for the confounding effect of inflating geopotential heights in a warming climate (Barnes 2013) and identifies potentially different subregional changes in the magnitude of SIN, such as those hypothesized to occur between places experiencing zonal wind increases versus decreases in the future.

\section{Results}

\section{a. Recent past}

To illustrate how sinuosity can quantify exceptional circulation states, we show the lowest and highest values of daily ASIN during the study period (Figs. 2a,b). A very zonally oriented flow with aggregate sinuosity of 1.04 occurred on 24 December 1951, associated with an extremely positive Arctic Oscillation (AO) index of +3.47 . In contrast, the remarkably muddled circulation pattern of 13 May 1993 yielded a record high ASIN of 2.64 , coincident with an extremely negative $-2.92 \mathrm{AO}$ index. Many extreme weather events coincide with high values of ASIN, such as the extreme cold-air outbreak in the United States in January 2014 and Superstorm Sandy in October 2012 (Figs. 2c,d), both of which occurred amid highly negative AO phases that are conducive to meridionally oriented circulation patterns and anomalously weak zonal flow across much of the midlatitudes (Thompson and Wallace 2001).

The mean annual cycle of ASIN in reanalysis exhibits a pronounced seasonal migration, ranging from a broad wintertime minimum around 1.3 to a somewhat narrower peak just above 1.6 during late spring and early summer (Fig. 3a). This cycle over the greater North American domain is similar to the hemispheric average obtained in MVWF, while the alternative sinuosity definition used in Cattiaux et al. (2016) results in a somewhat earlier annual maximum during spring. The higher waviness during warmer months is consistent with the observed maxima in blocking frequency during springtime (Barriopedro et al. 2006), cutoff lows during summer (Price and Vaughan 1992; Kentarchos and Davies 1998), and atmospheric wavenumber in summer (Willson 1975). Throughout the year there is a strongly inverse relationship between ASIN and zonal wind speed, such that waviness is higher (lower) when westerlies aloft are weaker (stronger), conforming with empirical evidence (Walsh 2014) and theory (Chen et al. 2015; Wang and Nakamura 2015; Huang and Nakamura 2016). The correlation coefficient between aggregate sinuosity and zonal wind speed is -0.61 for all days in the time series and -0.93 based on the climatological annual cycle shown in Fig. 3 a.

The annual cycle of aggregate sinuosity can be explained by the seasonality of the individual isohypses that constitute ASIN (Fig. 3b). The more southerly isohypses $(552,564$, and 576 dam) exhibit a peak during summer, indicating their dominant role in shaping ASIN. By contrast, the remaining isohypses (528 and $540 \mathrm{dam}$ ) feature a double peak, one in spring and one in fall, which coincides with the prevalence of cutoff lows in more northerly locations across the domain (MVWF). During summer, these isohypses migrate so far poleward that their meridional wave amplitude is constrained. LENS reproduces these major circulation features in the ensemble mean and shows a relatively small ensemble range (Figs. 3c,d), closely simulating the phasing of the annual cycle but with a somewhat sharper and elevated summer maximum. Likewise, the model reproduces the major features of individual isohypses, although it simulates a more distinct summertime sinuosity peak of the southernmost contour (576 dam).

Annually averaged ASIN exhibits an upward trend over the course of the study period that is significant at the $99 \%$ level, based on the Sen-Kendall method (Sen 1968) and a Mann-Kendall test (Mann 1945). Embedded within this positive tendency is pronounced 
(a) $\mathrm{ASIN}=1.04$

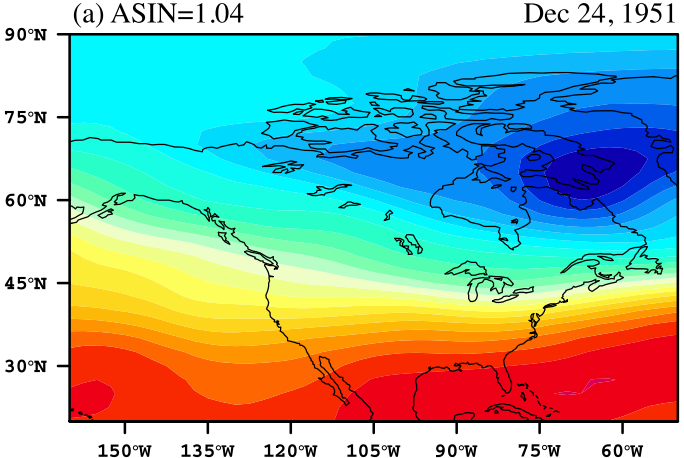

(c) $\mathrm{ASIN}=1.58$

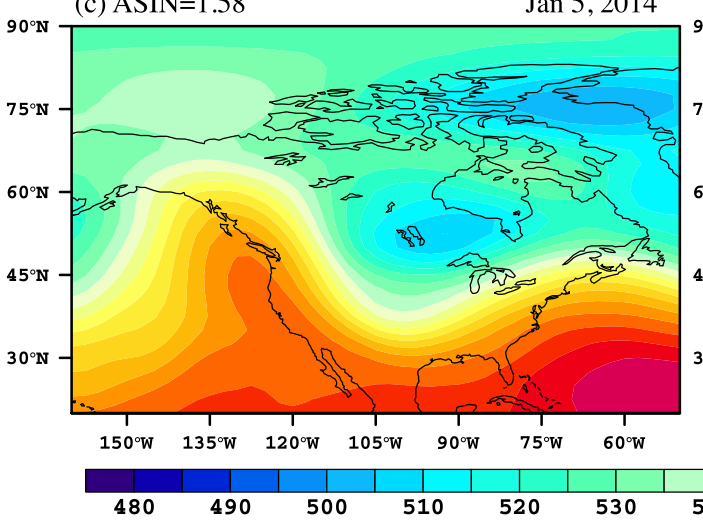

(b) $\mathrm{ASIN}=2.64$

May 13, 1993

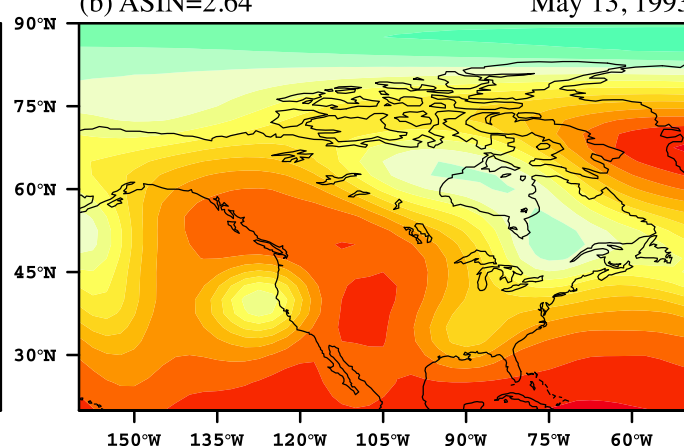

(d) ASIN $=1.8$

Oct 27,2012

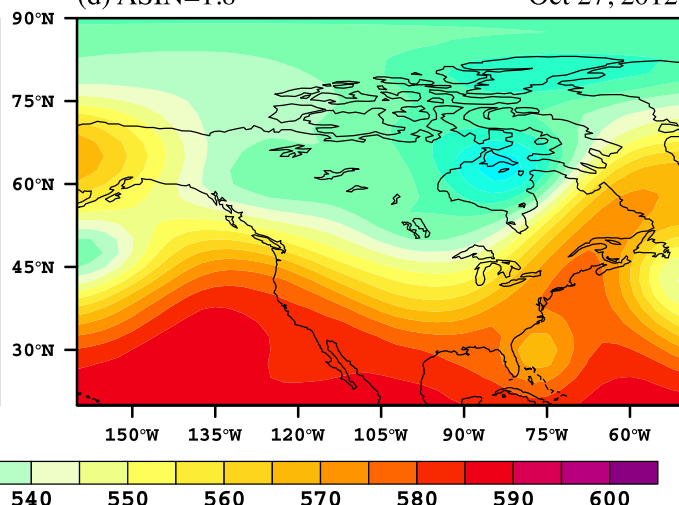

FIG. 2. Examples of noteworthy circulation states, illustrated by $500-\mathrm{hPa}$ geopotential heights [dekameter (dam)]. (a) Lowest ASIN on record (1.04), (b) highest ASIN (2.64), (c) extreme cold-air outbreak in January 2014 $($ ASIN $=95$ th percentile for January), and $(d)$ Superstorm Sandy (ASIN $=98$ th percentile for October).

interannual variability (Fig. 4) related closely to the annual AO index ( $r=-0.51 ; 99 \%$ significance level). This relationship is apparent in the two highest ASIN years (2009 and 2010) that coincide with very negative AO indices during winter 2009/10 (Cohen et al. 2010), as well as the lowest annual ASIN in more than 40 years occurring during the most positive AO year (1990). Daily variations in ASIN are significantly associated with the AO throughout the year, ranging from correlations of -0.40 (November) to -0.53 (March), in agreement with MVWF, Cattiaux et al. (2016), and Di Capua and Coumou (2016). The strongly inverse relationship between ASIN and the AO on daily-annual time scales indicates that sinuosity represents variations of circulation waviness prevailing across the midlatitudes as the polar vortex weakens and strengthens.

A potential problem with interpreting the long-term behavior of ASIN is that a warming climate inflates geopotential height contours, thus causing the reference isohypses to shift poleward and possibly confounding comparisons over time, as demonstrated by Barnes (2013). To circumvent this complication, we also examined trends in sinuosity by latitude during winter and summer (Fig. 5), whose intraseasonal trends are much more consistent than those in spring and autumn (not shown). The long-term behavior of SIN, as expressed by moving linear trends, varies with time and season, but a noteworthy feature is the consistently positive trends during winter and summer beginning around 1980 in mid-to-high latitudes that largely account for the increasing annual ASIN. Interestingly, this timing coincides with the start of reliable satellite records of Arctic sea ice and certain reanalysis products, such as ERA-Interim (Dee et al. 2011), that have been used to diagnose recent Arctic climate change. These recent upward trends in SIN generally align with downward trends in zonal wind speed aloft (Fig. 5), particularly during winter, reflecting their inverse relationship over the annual cycle shown in Fig. 3 and interannually (Cattiaux et al. 2016; PCVM).

\section{b. Simulated future changes}

Driven by strong greenhouse forcing, the simulated extratropical climate warms significantly in the future and features major circulation changes by late century. As shown in Fig. 6, the 40-member LENS average produces two general patterns of 500-hPa geopotential height anomalies: one that occurs during winter (NovemberMarch), exemplified by January, and the other during 


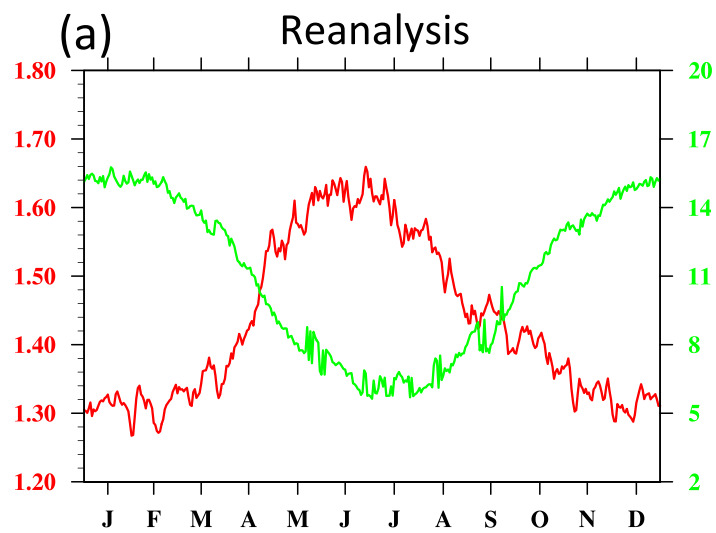

(b)

Reanalysis

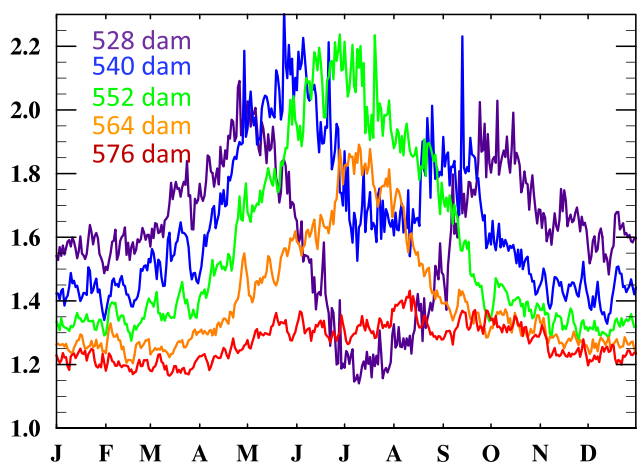

(d)
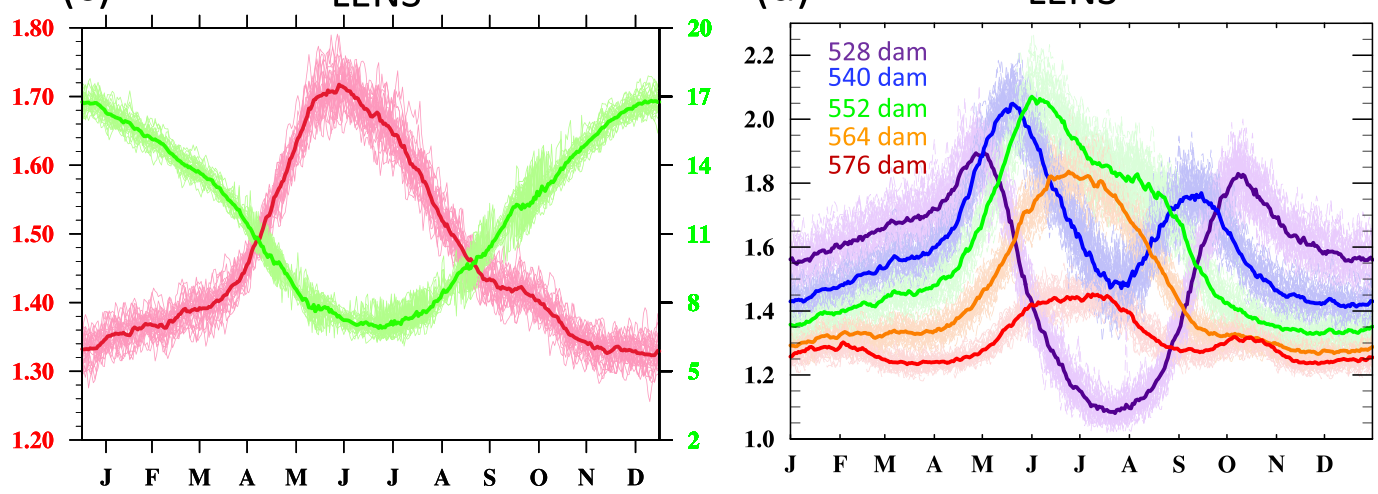

FIG. 3. Annual cycle of sinuosity and zonal wind speed $\left(\mathrm{m} \mathrm{s}^{-1}\right)$ at $500 \mathrm{hPa}$. Aggregate SIN from 1948 to 2014 in red and zonal wind speed in green from (a) reanalysis and (c) LENS. The zonal wind curve was calculated in the same weighted manner as aggregate SIN, based on the zonally averaged westerly wind speed across each isohypse. Zonally averaged sinuosity at individual isohypses comprising aggregate SIN from (b) reanalysis and (d) LENS. Individual ensemble members are shown in light shading, and ensemble means are represented by dark lines.

summer (June-September), represented by August (individual months are presented in Figs. S1-S3 in the supplemental material). The winter pattern is characterized by exceptionally strong surface heating in the Arctic, particularly over the Arctic Ocean (Fig. 6a), which experiences dramatic reductions in sea ice extent and thickness (not shown). Remarkably, near-surface temperatures rise by up to $25 \mathrm{~K}$ in January and promote major positive midtropospheric height anomalies aloft over most of the Arctic, as well as across most of the Eurasian midlatitudes. By contrast, heights fall in a relative sense to the south of the Arctic-based ridging anomaly, extending from the North Pacific to northern Europe and bearing some resemblance to the negative phase of the Arctic Oscillation (Fig. 6c). The associated changes in zonal winds are dictated by these pressure redistributions through the thermal wind relationship, such that weaker westerlies aloft across North America (centered mainly over Canada) are sandwiched between the anomalous ridging over the Arctic and anomalous troughing to the south, with maximum wind increases impinging on the Southern California coast (Fig. 6e). Conversely, the pressure redistribution over the Eastern Hemisphere causes a very different zonal wind response, featuring stronger speeds over most of western Europe but a widespread band of weaker westerlies across the entire southernmost part of the extratropics from the prime meridian to the date line.

The summertime climate changes (Figs. 6b,d) are very different from those during winter. There is a more uniform warming pattern over mid-to-high latitudes, with some of the most pronounced temperature increases occurring farther south, over midlatitude continents (Fig. 6b). Warming over western North America is particularly strong, reminiscent of recent years. This widespread surface warming is associated with very large geopotential height increases across the entire extratropics (Fig. 6d), indicative of the overall warmer Northern Hemisphere during boreal summer. A more important seasonal difference is the configuration of 


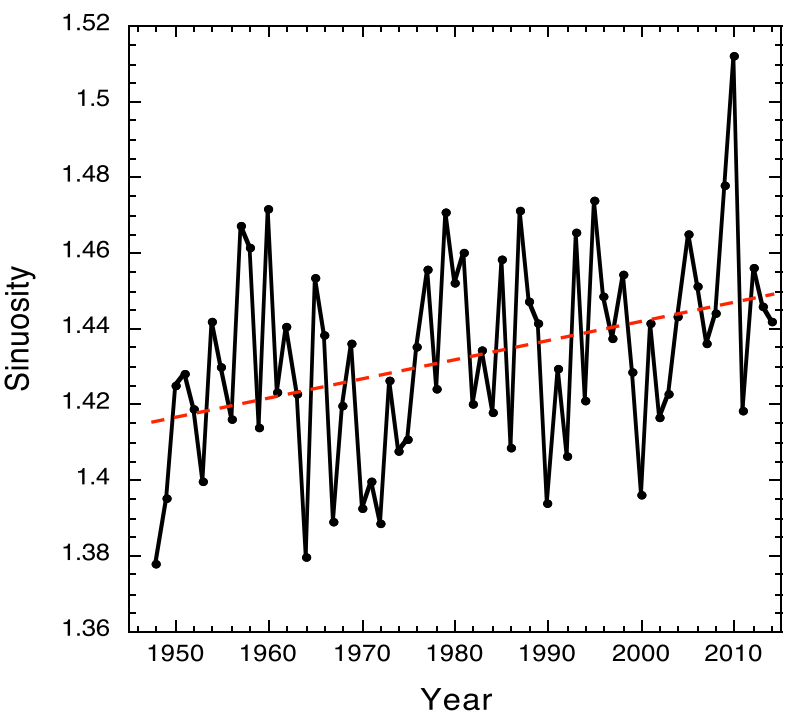

FIG. 4. Mean annual aggregate SIN and linear trend line from 1948 to 2014 using reanalysis data.

maximum height increases, which in summer are oriented in an annular pattern approximately centered around the location of greatest ridging over the central Arctic during winter. This summertime shift causes fairly coherent spatial changes in the speed of the zonal winds, which weaken over the entire Northern Hemisphere around $40^{\circ} \mathrm{N}$ and strengthen over most of the hemisphere around $60^{\circ} \mathrm{N}$ (Fig. 6f). The weakening of the westerlies is especially pronounced over North America, reaching 3-4 $\mathrm{m} \mathrm{s}^{-1}$ over the central United States, attributable to the enhanced ridging anomaly over western Canada that extends across the continent (Fig. 6d). This synoptic pattern is highly conducive to extreme heat and drought over the central United States (Chang and Wallace 1987; Mo et al. 1997; Rowell 2009) and is consistent with the documented weakening of midlatitude storm tracks and zonal wind in CMIP5 models (Chang et al. 2012; Lehmann et al. 2014; Coumou et al. 2015; Brewer and Mass 2016). In fact, the circulation changes in LENS during both winter and summer stem from geopotential height responses that are strikingly similar to those in CMIP5 (Fig. S4 in the supplemental material).

Despite the very different circulation responses between summer and winter, one commonality is the dipole pattern of zonal wind changes that emerges in both seasons, indicative of meridional shifts in the mean jet stream. This response is more complex than a general weakening of the extratropical circulation induced by AA, as hypothesized by FV12, but it closely conforms to the proposed mechanisms via the loss of sea ice and snow cover. Consistent with expectations, the simulated AA in these experiments promotes marine-based ridging over high latitudes during winter and terrestrialbased ridging over the northern extratropics during summer, both of which cause weaker westerlies aloft on their equatorward flanks. FV12 further hypothesized that the weaker circulation would lead to a wavier flow, a prediction that can be tested using the sinuosity metric. PCVM report that late twenty-first-century sinuosity in LENS decreased during winter and increased during summer (JJA) across the Northern Hemisphere overall, but opposite seasonal changes occurred in the North American sector. Because of the distinctly dipole response of the simulated zonal wind changes over North America, we opt here for an alternative to either using sinuosity or calculating sinuosity at a fixed latitude, as in PCVM. Instead, we calculate SIN at each latitude band to capture the potentially variable response of circulation waviness across greater North America.

The response of SIN and zonal wind is found to be highly inversely correlated, both in winter and summer (Fig. 7 and Fig. S5 in the supplemental material). The ensemble-mean sinuosity during winter is consistently lower south of $40^{\circ} \mathrm{N}$, where the zonal wind strengthens by up to $2 \mathrm{~m} \mathrm{~s}^{-1}$. Poleward of $40^{\circ} \mathrm{N}$ the zonal wind slackens by up to $2 \mathrm{~m} \mathrm{~s}^{-1}$, while SIN increases at almost all latitudes by approximately the same amount (0.050.10 ) and by nearly the same magnitude as the maximum decrease south of $40^{\circ} \mathrm{N}$. Inversely related changes in zonal wind and SIN also occur during summer and feature higher SIN between $35^{\circ}$ and $50^{\circ} \mathrm{N}$, in concert with weakened westerlies of up to $2 \mathrm{~m} \mathrm{~s}^{-1}$. A striking feature is the pronounced peak increase in sinuosity of around 0.8 at $42^{\circ} \mathrm{N}$ that is consistent with the sharp jump in climatological summertime SIN between $50^{\circ}$ and $40^{\circ} \mathrm{N}$ in the twentieth century (Fig. S6 in the supplemental material), characterized by more closed highs aloft when the circulation weakens during late summer. Sinuosity is sensitive to the presence of closed cyclones and anticyclones, whose isohypse length is extensive relative to equivalent length, and thus these features are exceptionally wavy by our metric (MVWF). In high latitudes the westerlies strengthen during August by up to $1.5 \mathrm{~m} \mathrm{~s}^{-1}$ at $60^{\circ} \mathrm{N}$, collocated with a maximum SIN reduction of nearly 0.2 , but then exhibit no significant changes poleward of $70^{\circ} \mathrm{N}$, where SIN declines modestly. In both seasons, the changes in SIN south of $30^{\circ} \mathrm{N}$ are less reliable, owing to difficulties in calculating this circulation metric where the wave structure becomes less coherent outside of the climatological westerlies. This increased uncertainty is illustrated by the large scatter among ensemble members in SIN changes at low latitudes during January, whereas the sign of the sinuosity changes is generally consistent among ensemble members at other latitudes in both seasons. 


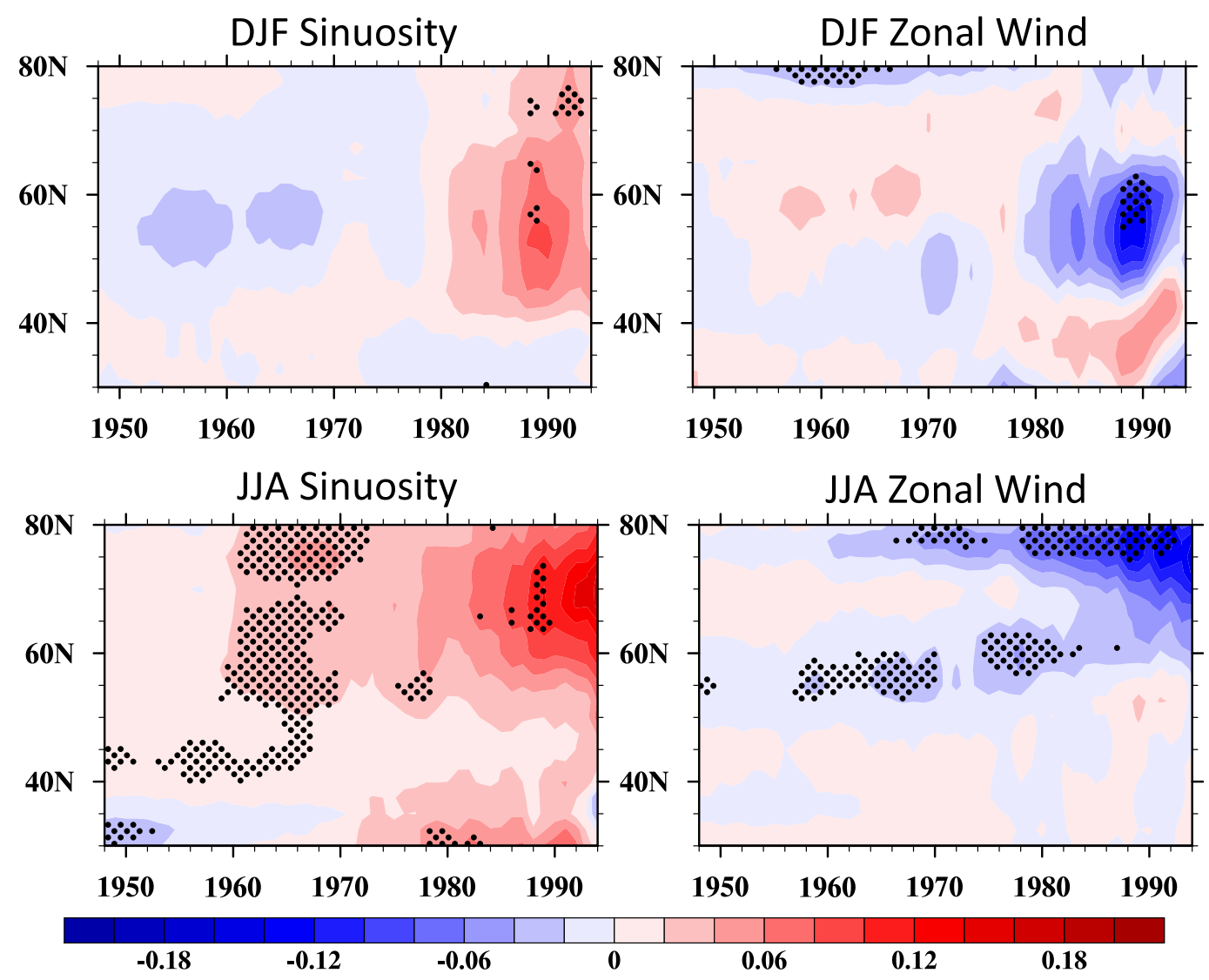

FIG. 5. Moving linear trends of (left) sinuosity (decade ${ }^{-1}$ ) and (right) 500-hPa zonal wind speed ( $\mathrm{m} \mathrm{s}^{-1} \mathrm{yr}^{-1}$ ) from reanalysis during (top) DJF and (bottom) JJA. The trends begin in a given year on the $x$ axis and end in 2014 . Stippling denotes significant trends at the $90 \%$ confidence level using a least squares regression.

\section{c. Relationship with extreme weather}

Our findings from LENS demonstrate that significant but spatially variable changes in the strength and waviness of the circulation over North America can be expected in the future. Because a sluggish, sinuous flow is often associated with extreme weather (Screen and Simmonds 2014; FV12), our results suggest that conditions will become more favorable for such anomalies over Canada and Alaska during winter and over much of the continental United States during summer. In particular, the very large sinuosity increase and weaker winds centered over the middle of the United States during summer warrants closer examination. The circulation change in this season should promote excess heat and drought, consistent with evidence of reduced cyclone activity (Lehmann et al. 2014; Coumou et al. 2015). Indeed, LENS simulates that interior North America will receive up to $1-2 \mathrm{~mm} \mathrm{day}^{-1}$ less August rainfall $(30 \%-50 \%)$ in the future (Fig. 8), roughly collocated with enhanced surface warming evident in Fig. 6b. The combination of these two changes promotes a strong loss of soil moisture that favors extreme heat and severe aridity in this region (Teng et al. 2016; Douville et al. 2016). Many climate model simulations have produced accentuated summer rainfall reductions in the Great Plains, including CMIP5 (Maloney et al. 2014), although there is not a consensus on the cause(s).

Our results suggest that the mean change in the large-scale circulation promotes enhanced heating and rainfall reductions, but the mean does not reveal the synoptic-scale expression of this climate change in terms of daily weather. To gain insight on that question, we first show the relationship in LENS between the strength of the flow aloft and the associated daily near-surface temperature and rainfall during August, averaged over the box of maximum drying in Fig. 8 ( $35^{\circ}-$ $45^{\circ} \mathrm{N}, 105^{\circ}-100^{\circ} \mathrm{W}$ ) that also encompasses the core of maximum zonal wind speed reduction. Simulated daily anomalies are a strong function of zonal wind speed, such that days with the weakest westerlies (or even easterlies) aloft are the warmest and driest (Figs. 9a-d). This relationship becomes especially strong and virtually monotonic in the future and features a particularly 

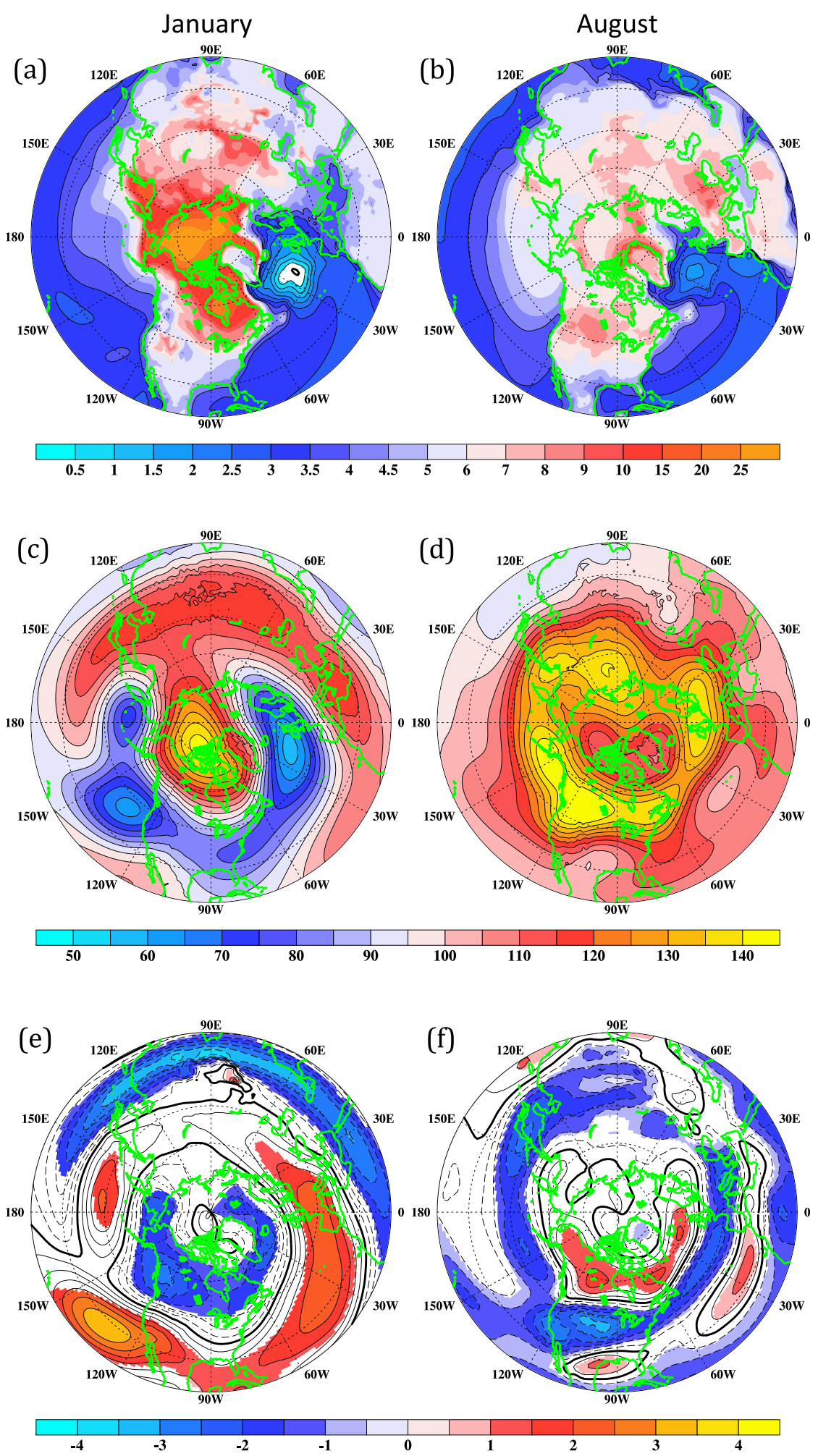

FIG. 6. Future changes (2081-2100 vs 1981-2000) in (a),(b) 2-m air temperature (K), (c),(d) 500-hPa heights (m), and (e),(f) 500-hPa zonal wind speed $\left(\mathrm{m} \mathrm{s}^{-1}\right)$ during (left) January and (right) August. Shaded regions denote where the ensemble-mean changes are larger than the standard deviation of the intraensemble changes. Dashed contours indicate where wind speed changes are negative. 

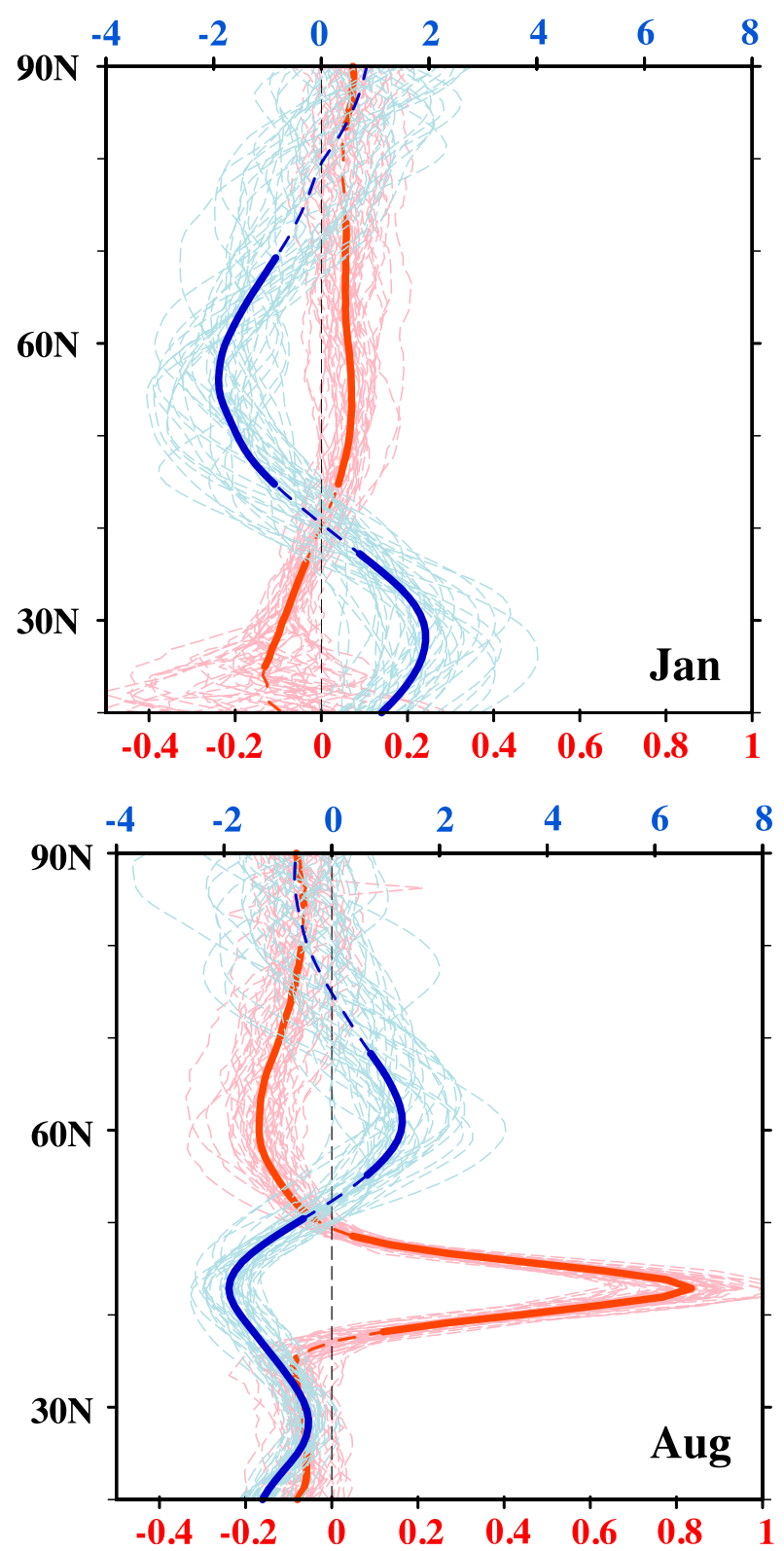

FIG. 7. Future changes (2081-2100 vs 1981-2000) in zonal wind speed ( $\mathrm{m} \mathrm{s}^{-1}$; blue; upper $x$ axis) and sinuosity (unitless; red; bottom $x$ axis) during (top) January and (bottom) August over the greater North American domain. Thin lines denote individual ensemble members, and thick lines are the ensemble average. Solid thick lines indicate where the ensemble-mean change exceeds the standard deviation of changes among all ensemble members.

large drop-off in rainfall at the far-left tail of the distribution that represents light easterly winds aloft. These results are consistent with prior studies that demonstrated a highly inverse relationship between summer temperature and rainfall over the Midwest (Madden and Williams 1978; Chang and Wallace 1987; Trenberth and Shea 2005).
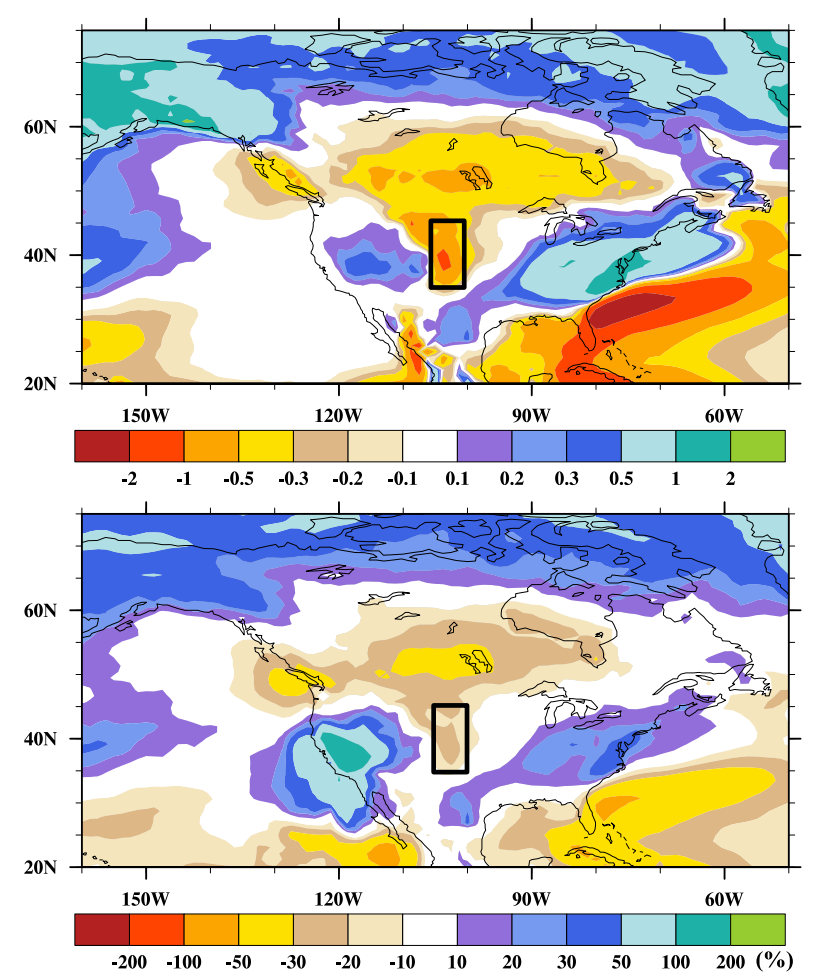

FIG. 8. Future changes (2081-2100 vs 1981-2000) in August precipitation expressed as (top) absolute difference $\left(\mathrm{mm} \mathrm{day}^{-1}\right)$ and (bottom) percentage difference. The box over the plains denotes the reference region of especially pronounced drying and heating.

This linkage between large-scale circulation and extreme weather means that the overall weakening and amplification of the summertime flow aloft over interior North America favors hotter and drier weather, but the breakdown of projected changes in the distribution of wind speeds yields additional information (Figs. 9e,f). The average weakening of the zonal circulation aloft is expressed as fewer days with strong flow and more days with weak flow. This change is especially pronounced for days with easterly winds, which occur less than $2 \%$ of the time in the late twentieth century but approximately $15 \%$ in the future simulation. A cleaner comparison between the two time periods can be made by calculating the percentage change in the frequency of wind speeds across the distribution, using equal-sized bins that each occupies $5 \%$ of the total (Fig. 9f). The shift in the distribution produces highly asymmetric changes, such that the frequency of days with easterlies or the lightest westerlies increases much more (up to $375 \%$ ) than the decline of the strongest westerlies. Because days with light winds are coincident with the driest and warmest conditions during both time periods (Figs. 9a-d), their spike in the future implies that circulation changes will contribute strongly to increased extreme summertime weather in this region. 
(a)

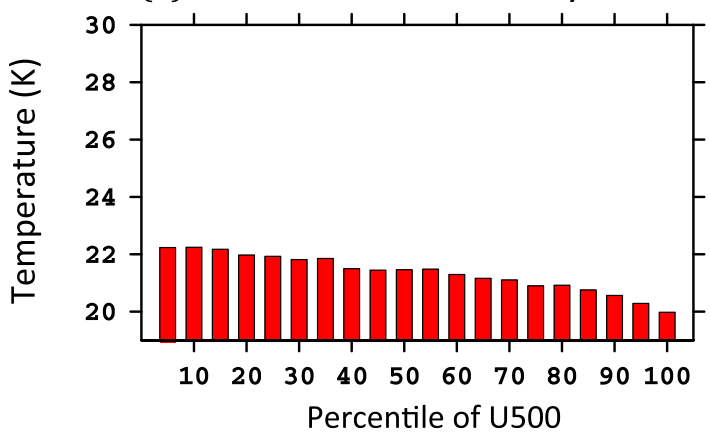

(c)

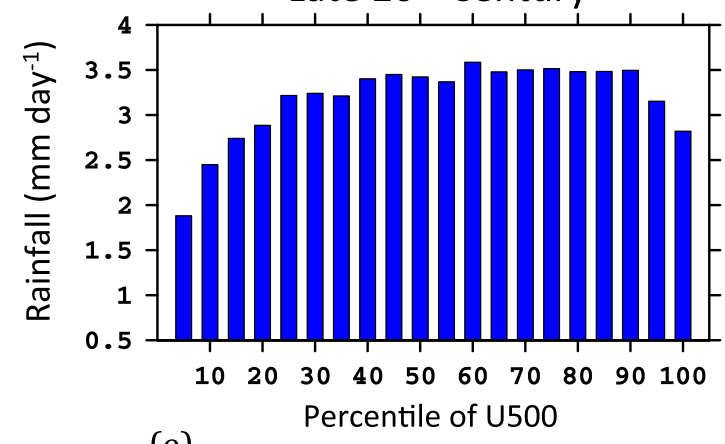

(e)

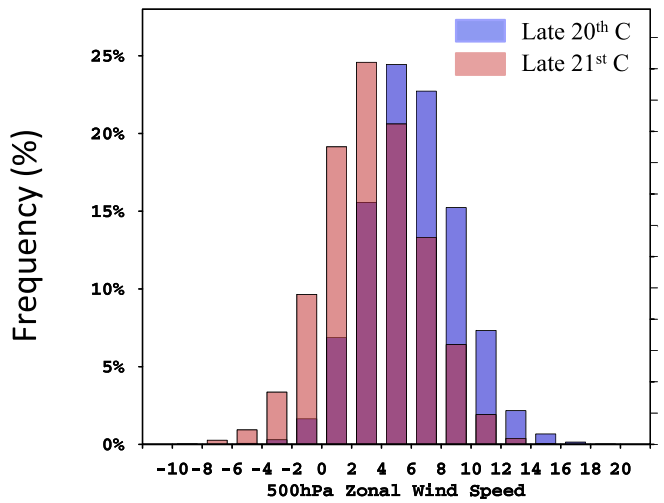

(b) Late $21^{\text {st }}$ Century

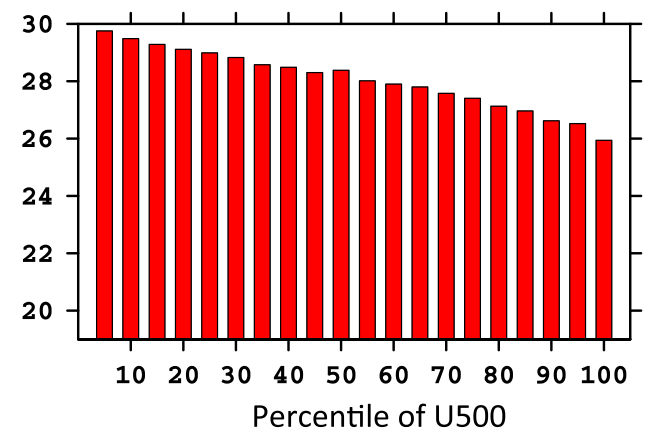

(d)

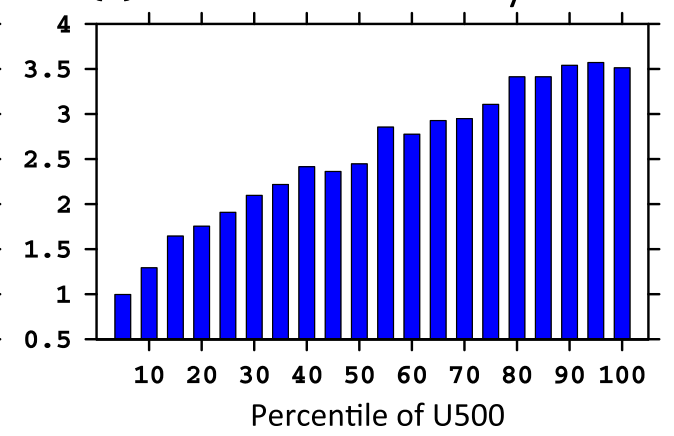

(f) Late $21^{\text {st }}-$ Late $20^{\text {th }}$ Century

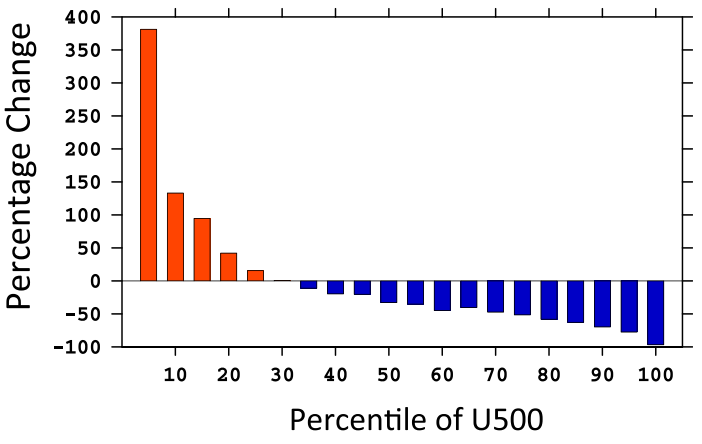

FIG. 9. Daily mean 2-m air temperatures and rainfall over the midcontinental box (see Fig. 8) for all August days as a function of the 500-hPa zonal wind speed (percentile) during the (a),(c) late twentieth century and (b), (d) late twenty-first century. High percentiles indicate a strong westerly wind aloft, and low percentiles represent either a weak westerly wind or an easterly wind. (e) Histogram of daily August wind speeds $\left(\mathrm{m} \mathrm{s}^{-1}\right)$ in the late twentieth and late twenty-first century. (f) Percentage change in August wind speed frequency during the late twenty-first century relative to the late twentieth century.

Further insight into the relationship between largescale circulation and weather impacts is found by compositing the large-scale circulation anomalies on the driest August months within the same box described above (Fig. 10). During these extremely dry months, the simulated circulation consists of an anomalous ridge to the north of the maximum midcontinental drying with anomalous easterly flow. The strength of the ridge also builds in the future and reaches up to a 30-m anomaly, compared with $20 \mathrm{~m}$ in the late twentieth century. These characteristic drought circulation patterns in both time periods resemble the mean summertime circulation change (Fig. 6d) and the observed pattern during midwestern droughts and heat waves (Mo et al. 1997; Lau and Nath 2012). This agreement provides further evidence that the mean shift toward a weaker, wavier summertime circulation favors drier, warmer conditions that promotes extreme aridity over the central United States. This dynamical signature further suggests that the excessive future drying and heating in this region is 


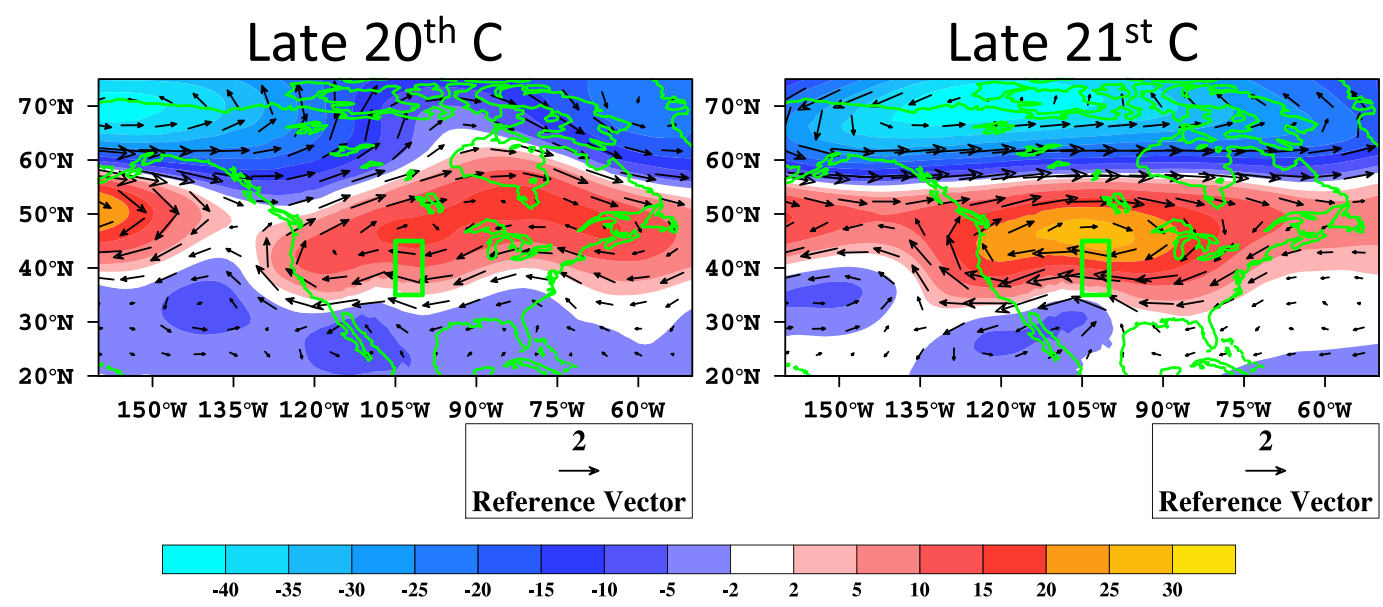

FIG. 10. The 500-hPa geopotential height $(\mathrm{m})$ and wind velocity $\left(\mathrm{m} \mathrm{s}^{-1}\right)$ anomalies in LENS on the driest $5 \%$ of August months during the (left) late twentieth century and (right) late twenty-first century, relative to each time period's climatology. The box corresponds to the region of enhanced drying and heating shown in Fig. 8.

unlikely to be caused exclusively by local soil-moisture feedbacks but rather that this aridity signal is significantly influenced by large-scale circulation changes.

\section{d. Role of higher latitudes}

A central open question is whether the projected summertime midlatitude circulation changes are a direct consequence of AA. Although the traditional perspective is that the dynamical contribution to midcontinental drying stems from a poleward expansion of the Hadley circulation and eddy-driven jet ( $\mathrm{Lu}$ et al. 2007; Rivière 2011) and thus is somewhat independent of high-latitude changes, an alternative explanation is that AA also plays a significant role by promoting the annular band of maximum ridging (Fig. 6d) through enhanced heating of mid-to-high-latitude continents.

Several lines of reasoning support this interpretation of an Arctic influence. First, simulated greenhouse warming causes a large reduction in continental snow cover during spring and early summer (Fig. 11), which promotes warming by lowering surface albedo and soil moisture (Matsumura and Yamazaki 2012; Crawford and Serreze 2015). Second, this enhanced surface warming is most pronounced in mid-to-high latitudes, where hemispheric land cover is most prevalent (between $45^{\circ}$ and $70^{\circ} \mathrm{N}$, peaking around $65^{\circ} \mathrm{N}$ ). Third, the much lower heat capacity of land versus water causes continents to warm more than adjacent oceans during summer, as is apparent in LENS (Fig. 6b). Alexander et al. (2010) showed that imposed snow-cover reductions in the CAM3 AGCM caused mid-to-high-latitude ridging during spring and summer, while observations demonstrate a similar relationship from interannual snowcover anomalies (Matsumura and Yamazaki 2012). In addition, an experiment using the CCSM3 GCM with all terrestrial snow cover eliminated (Vavrus 2007) produced amplified summertime surface warming locally and an annular band of ridging aloft that resembles the pattern produced in LENS (Fig. 12, left, and Fig. S7 in the supplemental material). Furthermore, these terrestrially based heating sources can generate standing Rossby waves that are advected downstream by adiabatic warming from descending air masses and the prevailing westerlies aloft (Rowell 2009; Matsumura and Yamazaki 2012; Matsumura et al. 2014). Indeed, the strongest $500-\mathrm{hPa}$ zonal winds during summer in the late twenty-first-century LENS simulations (Fig. S8 in the supplemental material) are closely aligned with the band of maximum 500-hPa height increases (Fig. 6d), particularly over the oceans. In this manner, enhanced terrestrial warming during summer over mid-to-high latitudes can initiate the annular band of maximum ridging simulated by LENS, very similar to the circumhemispheric band of 500-hPa height anomalies found to be most highly correlated with projected summer rainfall reductions over western North America and Europe from greenhouse forcing (Rowell 2009). Over North America, the location of the band of inflated heights that peaks over western Canada (Fig. 6d) is highly conducive to the simulated rainfall reductions in the plains.

An Arctic-oriented remote influence may exacerbate known factors related to local soil-moisture feedbacks (Wetherald and Manabe 1999; Gregory et al. 1997; Su et al. 2014) and an expanded subtropical aridity belt ( $\mathrm{Lu}$ et al. 2007; Scheff and Frierson 2012) as sources of midcontinental drying during summer, and it could be an important contributor to promoting the ridging pattern favorable for drought that is also simulated in the 

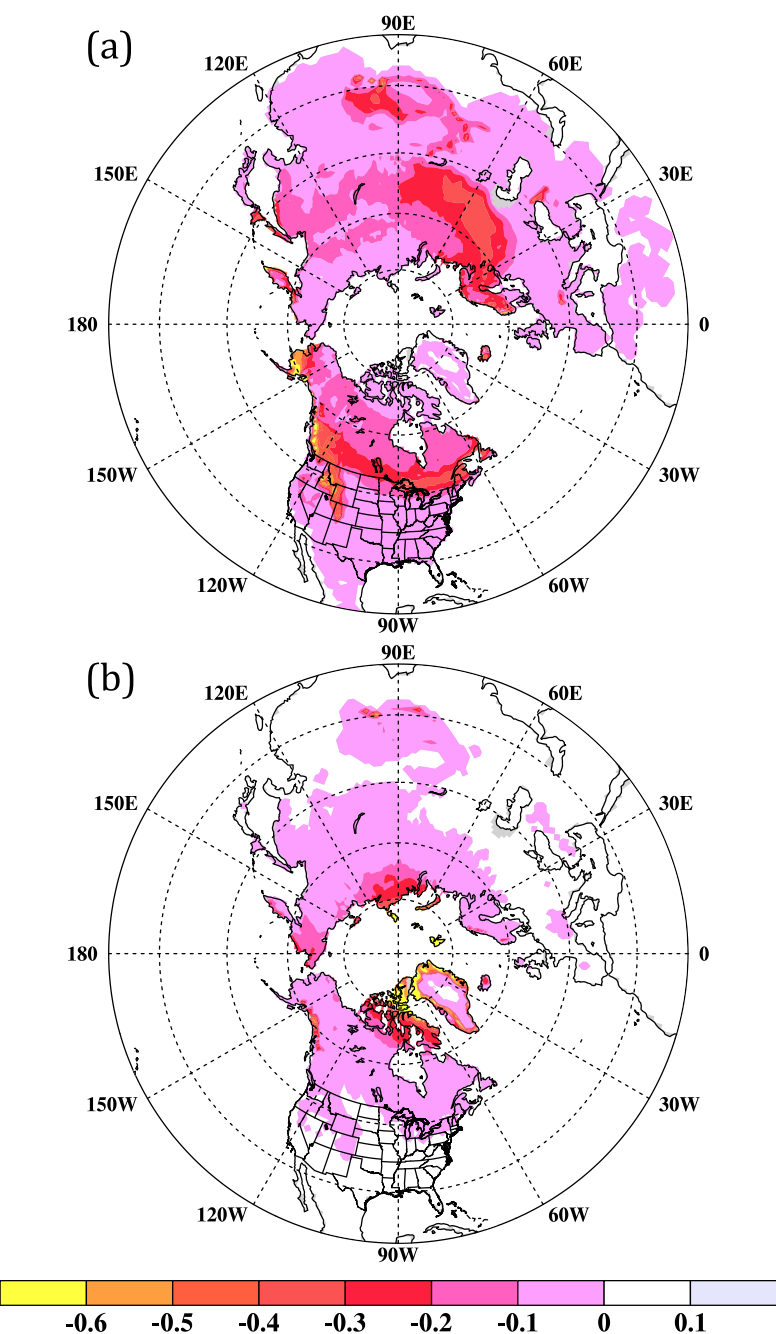

FIG. 11. Future changes (2081-2100 vs 1981-2000) in (a) MAM and (b) JJA snow fraction averaged among all ensemble members in LENS.

CMIP5 ensemble (Fig. S4; Maloney et al. 2014; Brewer and Mass 2016). Evidence from other studies also allows for nontraditional sources of possible teleconnective drivers, as in Rowell (2009) and Rowell and Jones (2006), who determined that remote circulation anomalies originating in the tropics contribute little to projected continental drying in Europe and North America. Similarly, Lu et al. (2007) concluded that future Hadley cell expansion and the associated poleward shift of the subtropical dry zone is unlikely to originate from tropical processes but rather is highly correlated with the extratropical tropopause height. The annular pattern of ridging anomalies identified here is different from the circumglobal teleconnection (CGT; Yang et al. 2009) because the ridging band in LENS is much farther north and there is no characteristic ridge to the northwest of India in LENS (a key feature of the monsoon-driven
CGT). Also, the CGT structure is equivalent barotropic, but the LENS response over land is a mix of barotropic and baroclinic (not shown).

Further support for a terrestrially driven, highlatitude circulation contribution comes from a CCSM4 paleoclimate simulation of 6000 years ago, when differences in Earth's orbital configuration caused much more summertime insolation in the Northern Hemisphere, especially in high latitudes (Otto-Bliesner et al. 2006). As with greenhouse forcing, the strongest summer warming occurred on mid-to-high-latitude land and was also associated with a circumhemispheric band of 500 -hPa height increases that resembles the LENS response, despite widespread tropical cooling (Fig. 12, right). Moreover, the teleconnection identified by Meehl and Tebaldi (2004) of enhanced Indian monsoon rainfall driving a mid-to-high-latitude band of ridging under greenhouse forcing does not explain the hemispheric-scale response in LENS. Although LENS also simulates greater monsoonal rainfall in the future, summers with more (less) rainfall are instead associated with lower (higher) geopotential heights aloft in a band stretching from Asia to North America (Fig. S9 in the supplemental material). By contrast, the strength of the zonal wind over the North American sector was found by PCVM to have a strong negative correlation with the magnitude of AA among LENS ensemble members. Deciphering the definitive role of higher latitudes in the summertime circulation changes described here requires additional investigation and will benefit from further modeling experiments.

\section{Discussion and conclusions}

Our study leads to the following conclusions regarding atmospheric circulation changes over North America and their possible connection with the Arctic:

- We find evidence for an increasing trend in mean annual waviness during the past several decades, superimposed on strong interannual variations associated with the phase of the AO, in agreement with Francis and Skific (2015), FV15, and Di Capua and Coumou (2016).

- There is a strong inverse relationship between projected changes in zonal wind speed and waviness, consistent with the intermodel CMIP5 and intraensemble LENS correlations identified in Cattiaux et al. (2016) and PCVM.

- This negative correlation occurs in both winter and summer, but the alignment of the circulation changes across the domain nearly reverses between seasons. A dipole pattern of weaker (stronger) westerlies arises in low to midlatitudes during summer (winter), and generally stronger (weaker) westerlies develop in higher latitudes during summer (winter). 
Surface Temperature (K)

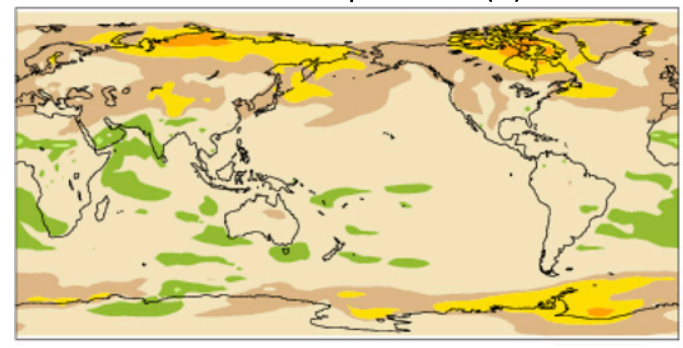

\begin{tabular}{lllllll|}
\hline & 1 & $\mid$ & $\mid$ & $\mid$ & $\mid$ & $\mid$ \\
\hline-4 & -2 & -1 & 0 & 1 & 2 & 4
\end{tabular}

$500 \mathrm{hPa}$ Heights (hm)

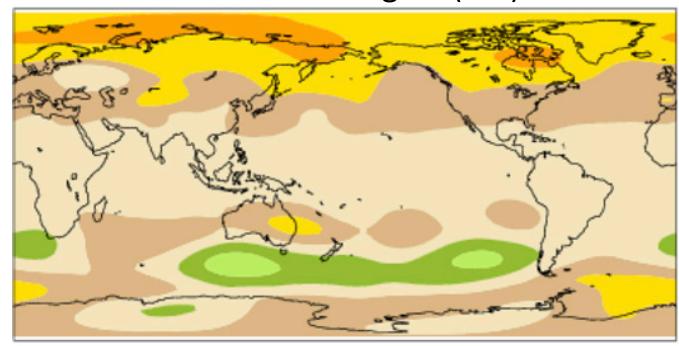

$\begin{array}{lllllll} & 0.4 \cdot 0.2 & -0.1 & 0 & 0.1 & 0.2 & 0.4\end{array}$

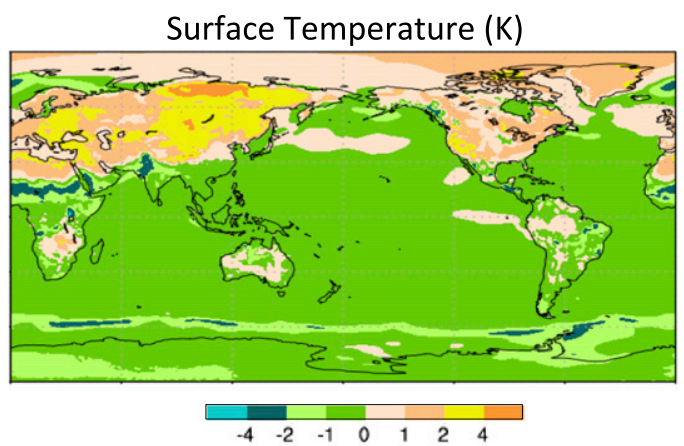

$500 \mathrm{hPa}$ Heights (hm)

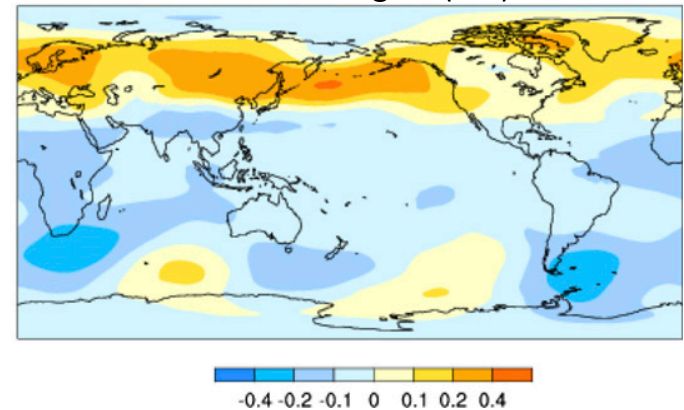

FIG. 12. Simulated changes in 2-m air temperature and 500-hPa geopotential heights [hectometer (hm)] during June-August in two climate model simulations that produced amplified high-latitude warming. (left) CCSM3 driven by contemporary greenhouse forcing (year 1990) but with all terrestrial snow cover eliminated (from Vavrus 2007). (right) CCSM4 paleoclimate simulation of 6000 years ago minus year 1850 driven by differences in Earth's orbital configuration between the two time periods.

- Simulations suggest a trend toward a future circulation pattern conducive to extreme drying and heating in central North America during summer, particularly in association with greater instances of easterly flow aloft.

- This circulation change appears to be fostered by the enhanced summertime heating of continents in midto-high latitudes, which promotes an annular band of maximum height increases across the entire Northern Hemisphere. The amplified warmth over land and its remote influence are favored by diminishing snow cover and low terrestrial heat capacity in latitudes where land is especially prevalent.

Our analysis focuses on greater North America because its projected response to greenhouse forcing is considerably different from elsewhere in the Northern Hemisphere (Fig. 6; Cattiaux et al. 2016; PCVM). A distinguishing finding of this study is the latitudinally varying response of projected seasonal circulation changes, which reveal dipole changes in circulation vigor and waviness from north to south that are related to meridional shifts in jet stream location. This differentiation contrasts with the "block" approach taken by Barnes and Polvani (2015), who concluded that CMIP5 models generally simulate a weak Arctic influence on future circulation characteristics over the greater North
American-Atlantic region, based on domain averages from $30^{\circ}$ to $70^{\circ} \mathrm{N}$. Our study also refines recent findings by Cattiaux et al. (2016) and PCVM, whose conclusions of future circulation changes in the CMIP5 and LENS simulations, respectively, were based on sinuosity centered at a fixed latitude $\left(\sim 50^{\circ} \mathrm{N}\right)$. Both of these studies identified a future increase (decrease) in sinuosity during winter (summer) over the North American sector, but our results demonstrate that this average response is the result of opposing changes in different zones within the domain.

One motivation for this work was to test the hypothesis of FV12 that Arctic amplification would lead to a weaker and wavier midlatitude circulation that is more conducive to prolonged extreme weather events. Our results provide partial support for this hypothesis but reveal that the extratropical response is more geographically varied than implied by that study. FV12's central physical mechanism is supported by our results, in that simulated AA promotes ridging in mid-to-high latitudes that weakens the zonal wind on the equatorward flank and leads to a wavier (more sinuous) flow. However, this response is not uniform across the entire extratropical domain; instead, we find that some areas exhibit the opposite pattern of troughing, stronger zonal winds, and reduced waviness. 
An open question is the extent to which the enhanced westerlies around $30^{\circ} \mathrm{N}$ during winter (Fig. 6e) originate from a tropically induced strengthening of the meridional height gradient, as opposed to a direct mass-compensation response to AA itself (Fig. 6c). For example, during a negative $\mathrm{AO}$ phase the characteristic high-latitude ridging anomaly is offset by a midlatitude troughing anomaly (Thompson and Wallace 1998) associated with stronger westerlies on its equatorward flank that resembles the atmospheric response to tropical warming during $\mathrm{El}$ Niños. Because greenhouse forcing causes warming and height inflation in upper levels of the tropical troposphere as well as in the lower polar troposphere (Held 1993; Barnes and Screen 2015; Cattiaux et al. 2016), isolating the Arctic contribution to the strengthened westerlies during winter in the LENS simulations is difficult. Further complicating this issue is the fact that Arctic warming is associated with temperature increases elsewhere, thus leading indirectly to tropical heating anomalies. However, some resolution of these competing influences is found in the CCSM4 experiments with prescribed future reductions in Arctic sea ice by Deser et al. (2015), which showed that the induced Arctic warming from ice loss alone caused additional warming in the upper-troposphere tropics along with significantly stronger westerlies between $30^{\circ}$ and $40^{\circ} \mathrm{N}$-even excluding SST changes elsewhere in the world-suggesting that the additional tropical heating in their fully coupled simulation further strengthened the zonal winds in this band.

Although our study does not provide a conclusive answer to the role of the Arctic in affecting midlatitude atmospheric circulation and weather extremes, it does augment the body of evidence suggesting that AA exerts a remote climatic influence that is highly variable by both latitude and season. In particular, our findings point to a potentially important contribution from enhanced terrestrial Arctic warming during spring-summer, a piece of the story that has been overshadowed by the widespread research focus on wintertime heating from sea ice loss. However, the recent decline in hemispheric spring snow-cover extent has actually outpaced the corresponding reduction in sea ice coverage in both absolute and relative terms (Derksen and Brown 2012). Assuming that spring snow extent will continue its downward trend, the results from LENS suggest that this change may have important repercussions beyond the Arctic by influencing the large-scale extratropical circulation in a way that helps to explain the commonly simulated drying and enhanced heating of interior North America.

Acknowledgments. This project has been supported by NSF Grants PLR-1304398, PLR-1304097, AGS-1407360,
AGS-1203430, and AGS-1602771. Computing resources on the Yellowstone supercomputer were provided by NCAR's Computational and Information Systems Laboratory, sponsored by the National Science Foundation.

\section{REFERENCES}

Alexander, M. A., R. Tomas, C. Deser, and D. M. Lawrence, 2010: The atmospheric response to projected terrestrial snow changes in the late twenty-first century. J. Climate, 23, 64306437, doi:10.1175/2010JCLI3899.1.

Barnes, E. A., 2013: Revisiting the evidence linking Arctic amplification to extreme weather in midlatitudes. Geophys. Res. Lett., 40, 4734-4739, doi:10.1002/grl.50880.

— , and L. M. Polvani, 2015: CMIP5 projections of Arctic amplification, of the North American/North Atlantic circulation, and of their relationship. J. Climate, 28, 5254-5271, doi:10.1175/ JCLI-D-14-00589.1.

- and J. A. Screen, 2015: The impact of Arctic warming on the midlatitude jet-stream: Can it? Has it? Will it? Wiley Interdiscip. Rev.: Climate Change, 6, 277-286, doi:10.1002/wcc.337.

_, E. Dunn-Sigouin, G. Masato, and T. Woolings, 2014: Exploring recent trends in Northern Hemisphere blocking. Geophys. Res. Lett., 41, 638-644, doi:10.1002/2013GL058745.

Barriopedro, D., R. García-Herrera, A. R. Lupo, and E. Hernandez, 2006: A climatology of Northern Hemisphere blocking. J. Climate, 19, 1042-1063, doi:10.1175/JCLI3678.1.

Brewer, M. C., and C. F. Mass, 2016: Projected changes in western U.S. large-scale summer synoptic circulations and variability in CMIP5 models. J. Climate, 29, 5965-5978, doi:10.1175/ JCLI-D-15-0598.1.

Cattiaux, J., Y. Peings, D. Saint-Martin, N. Trou-Kechout, and S. J. Vavrus, 2016: Sinuosity of midlatitude atmospheric flow in a warming world. Geophys. Res. Lett., 43, 8259-8268, doi:10.1002/ 2016GL070309.

Chang, E. K. M., Y. Guo, and X. Xia, 2012: CMIP5 multimodel ensemble projection of storm track change under global warming. J. Geophys. Res., 117, D23118, doi:10.1029/ 2012JD018578.

Chang, F.-C., and J. M. Wallace, 1987: Meteorological conditions during heat waves and droughts in the United States Great Plains. Mon. Wea. Rev., 115, 1253-1269, doi:10.1175/1520-0493(1987)115<1253: MCDHWA $>2.0 . C O ; 2$.

Chen, G., J. Lu, D. A. Burrows, and L. R. Leung, 2015: Local finiteamplitude wave activity as an objective diagnostic of midlatitude extreme weather. Geophys. Res. Lett., 42, 10 952-10960, doi:10.1002/2015GL066959.

Cohen, J., J. Foster, M. Barlow, K. Saito, and J. Jones, 2010: Winter 2009-2010: A case study of an extreme Arctic Oscillation event. Geophys. Res. Lett., 37, L17707, doi:10.1029/2010GL044256.

—, and Coauthors, 2014: Recent Arctic amplification and extreme mid-latitude weather. Nat. Geosci., 7, 627-637, doi:10.1038/ ngeo2234.

Coumou, D., J. Lehmann, and J. Beckmann, 2015: The weakening summer circulation in the Northern Hemisphere mid-latitudes. Science, 348, 324-327, doi:10.1126/science.1261768.

Crawford, A., and M. Serreze, 2015: A new look at the summer Arctic frontal zone. J. Climate, 28, 737-754, doi:10.1175/ JCLI-D-14-00447.1.

Dee, D. P., and Coauthors, 2011: The ERA-Interim reanalysis: Configuration and performance of the data assimilation system. Quart. J. Roy. Meteor. Soc., 137, 553-597, doi:10.1002/ qj. 828 . 
Derksen, C., and R. Brown, 2012: Spring snow cover extent reductions in the 2008-2012 period exceeding climate model projections. Geophys. Res. Lett., 39, L19504, doi:10.1029/ 2012 GL053387.

Deser, C., R. A. Tomas, and L. Sun, 2015: The role of oceanatmosphere coupling in the zonal-mean atmospheric response to Arctic sea ice loss. J. Climate, 28, 2168-2186, doi:10.1175/ JCLI-D-14-00325.1.

Di Capua, G., and D. Coumou, 2016: Changes in meandering of the Northern Hemisphere circulation. Environ. Res. Lett., 11, 094028, doi:10.1088/1748-9326/11/9/094028.

Douville, H., J. Colin, E. Krug, J. Cattiaux, and S. Thao, 2016: Midlatitude daily summer temperatures reshaped by soil moisture under climate change. Geophys. Res. Lett., 43, 812818, doi:10.1002/2015GL066222.

Francis, J. A. and S. J. Vavrus, 2012: Evidence linking Arctic amplification to extreme weather in mid-latitudes. Geophys. Res. Lett., 39, L06801, doi:10.1029/2012GL051000.

_- and N. Skific, 2015: Evidence linking rapid Arctic warming to mid-latitude weather patterns. Philos. Trans. Roy. Soc. London, 373A, 20140170, doi:10.1098/rsta.2014.0170.

— sponse to rapid Arctic warming. Environ. Res. Lett., 10, 014005 , doi:10.1088/1748-9326/10/1/014005.

Gleason, K. L., J. H. Lawrimore, D. H. Levinson, T. R. Karl, and D. J. Karoly, 2008: A revised U.S. climate extremes index. J. Climate, 21, 2124-2137, doi:10.1175/2007JCLI1883.1.

Gregory, J. M., J. F. B. Mitchell, and A. J. Brady, 1997: Summer drought in northern midlatitudes in a time-dependent $\mathrm{CO}_{2}$ climate experiment. J. Climate, 10, 662-686, doi:10.1175/ 1520-0442(1997)010<0662:SDINMI $>2.0 . C O ; 2$.

Held, I., 1993: Large-scale dynamics and global warming. Bull. Amer. Meteor. Soc., 74, 228-241, doi:10.1175/1520-0477(1993)074<0228: $\mathrm{LSDAGW}>2.0 . \mathrm{CO} ; 2$.

Honda, M., J. Inoue, and S. Yamane, 2009: Influence of low Arctic sea-ice minima on anomalously cold Eurasian winters. Geophys. Res. Lett., 36, L08707, doi:10.1029/2008GL037079.

Huang, C. S., and N. Nakamura, 2016: Local finite-amplitude wave activity as a diagnostic of anomalous weather events. J. Atmos. Sci., 73, 211-229, doi:10.1175/JAS-D-15-0194.1.

Kalnay, E., and Coauthors, 1996: The NCEP/NCAR 40-Year Reanalysis Project. Bull. Amer. Meteor. Soc., 77, 437-471, doi:10.1175/1520-0477(1996)077<0437:TNYRP>2.0.CO;2.

Kay, J. E., and Coauthors, 2015: The Community Earth System Model (CESM) Large Ensemble Project: A community resource for studying climate change in the presence of internal climate variability. Bull. Amer. Meteor. Soc., 96, 1333-1349, doi:10.1175/BAMS-D-13-00255.1.

Kennedy, D., T. Parker, T. Woolings, B. Harvey, and L. Shaffrey, 2016: The response of high-impact blocking weather systems to climate change. Geophys. Res. Lett., 43, 7250-7258, doi:10.1002/ 2016GL069725.

Kentarchos, A. S., and T. D. Davies, 1998: A climatology of cut-off lows at $200 \mathrm{hPa}$ in the Northern Hemisphere, 1990-1994. Int. J. Climatol., 18, 379-390, doi:10.1002/(SICI)1097-0088(19980330)18:4<379:: AID-JOC257>3.0.CO;2-F.

Knutti, R., D. Masson, and A. Gettelman, 2013: Climate model genealogy: Generation CMIP5 and how we got there. Geophys. Res. Lett., 40, 1194-1199, doi:10.1002/grl.50256.

Kug, J.-S., J.-H. Jeong, Y.-S. Jang, B.-M. Kim, C. K. Folland, S.-K. Min, and S.-W. Son, 2015: Two distinct influences of Arctic warming on cold winters over North America and East Asia. Nat. Geosci., 8, 759-762, doi:10.1038/ngeo2517.
Lau, N.-C., and M. J. Nath, 2012: A model study of heat waves over North America: Meteorological aspects and projections for the twenty-first century. J. Climate, 25, 4761-4784, doi:10.1175/ JCLI-D-11-00575.1.

Lehmann, J., D. Coumou, K. Frieler, A. V. Eliseev, and A. Levermann, 2014: Future changes in extratropical storm tracks and baroclinicity under climate change. Environ. Res. Lett., 9, 084002, doi:10.1088/1748-9326/9/8/084002.

Liu, J., J. A. Curry, H. Wang, M. Song, and R. M. Horton, 2012: Impact of declining Arctic sea ice on winter snowfall. Proc. Natl. Acad. Sci. USA, 109, 4074-4079, doi:10.1073/pnas.1114910109.

Lu, J., G. A. Vecchi, and T. Reichler, 2007: Expansion of the Hadley cell under global warming. Geophys. Res. Lett., 34, L06805, doi:10.1029/2006GL028443.

Madden, R. A., and J. Williams, 1978: The correlation between temperature and precipitation in the United States and Europe. Mon. Wea. Rev., 106, 142-147, doi:10.1175/1520-0493(1978)106<0142: TCBTAP $>2.0 . \mathrm{CO} ; 2$.

Maloney, E. D., and Coauthors, 2014: North American climate in CMIP5 experiments: Part III: Assessment of twenty-firstcentury projections. J. Climate, 27, 2230-2270, doi:10.1175/ JCLI-D-13-00273.1.

Mann, H. B., 1945: Nonparametric tests against trend. Econometrica, 13, 245-259, doi:10.2307/1907187.

Matsumura, S., and K. Yamazaki, 2012: Eurasian subarctic summer climate in response to anomalous snow cover. J. Climate, $\mathbf{2 5}$, 1305-1317, doi:10.1175/2011JCLI4116.1.

_- X. Zhang, and K. Yamazaki, 2014: Summer Arctic atmospheric circulation response to spring Eurasian snow cover and its possible linkage to accelerated sea ice decrease. J. Climate, 27, 6551-6558, doi:10.1175/JCLI-D-13-00549.1.

Meehl, G. A., and C. Tebaldi, 2004: More intense, more frequent, and longer lasting heat waves in the 21 st century. Science, $\mathbf{3 0 5}$, 994-997, doi:10.1126/science.1098704.

Mo, K. C., J. N. Paegle, and R. W. Higgins, 1997: Atmospheric processes associated with summer floods and droughts in the central United States. J. Climate, 10, 3028-3046, doi:10.1175/ 1520-0442(1997)010<3028:APAWSF > 2.0.CO;2.

Nakamura, N., 1996: Two-dimensional mixing, edge formation, and permeability diagnosed in an area coordinate. J. Atmos. Sci., 53, 1524-1537, doi:10.1175/1520-0469(1996)053<1524: TDMEFA $>2.0 . \mathrm{CO} ; 2$.

— , and A. Solomon, 2010: Finite-amplitude wave activity and mean flow adjustments in the atmospheric general circulation. Part I: Quasigeostrophic theory and analysis. J. Atmos. Sci., 67, 3967-3983, doi:10.1175/2010JAS3503.1.

Newson, R. L., 1973: Response of a general circulation model of the atmosphere to removal of the Arctic ice cap. Nature, 241, 39-40, doi:10.1038/241039b0.

Otto-Bliesner, B. L., E. C. Brady, G. Clauzet, R. Tomas, S. Levis, and Z. Kothavala, 2006: Last Glacial Maximum and Holocene climate in CCSM3. J. Climate, 19, 2526-2544, doi:10.1175/ JCLI3748.1.

Overland, J. E., J. A. Francis, R. Hall, E. Hanna, S.-J. Kim, and T. Vihma, 2015: The melting Arctic and midlatitude weather patterns: Are they connected? J. Climate, 28, 7917-7932, doi:10.1175/JCLI-D-14-00822.1.

Petoukhov, V., and V. Semenov, 2010: A link between reduced Barents-Kara sea ice and cold winter extremes over northern continents. J. Geophys. Res., 115, D21111, doi:10.1029/ 2009JD013568.

— S. Rahmstorf, S. Petri, and H. J. Schellnhuber, 2013: Quasiresonant amplification of planetary waves and recent 
Northern Hemisphere weather extremes. Proc. Natl. Acad. Sci. USA, 110, 5336-5341, doi:10.1073/pnas.1222000110.

Price, J. D., and G. Vaughan, 1992: Statistical studies of cutoff-low systems. Ann. Geophys., 10, 96-102.

Rivière, G., 2011: A dynamical interpretation of the poleward shift of the jet streams in global warming scenarios. J. Atmos. Sci., 68, 1253-1272, doi:10.1175/2011JAS3641.1.

Rohli, R. V., K. M. Wrona, and M. J. McHugh, 2005: January Northern Hemisphere circumpolar vortex variability and its relationship with hemispheric temperature and regional teleconnections. Int. J. Climatol., 25, 1421-1436, doi:10.1002/joc.1204.

Rossby, C.-G., and Coauthors, 1939: Relation between variations in the intensity of the zonal circulation of the atmosphere and the displacements of the semi-permanent centers of action. J. Mar. Res., 2, 38-54.

Rowell, D. P., 2009: Projected midlatitude continental summer drying: North America versus Europe. J. Climate, 22, 28132833, doi:10.1175/2008JCLI2713.1.

— summer drying over Europe. Climate Dyn., 27, 281-299, doi:10.1007/s00382-006-0125-9.

Scheff, J., and D. M. W. Frierson, 2012: Robust future precipitation declines in CMIP5 largely reflect the poleward expansion of model subtropical dry zones. Geophys. Res. Lett., 39, L18704, doi:10.1029/2012GL052910.

Screen, J. A., and I. Simmonds, 2013: Exploring links between Arctic amplification and mid-latitude weather. Geophys. Res. Lett., 40, 959-964, doi:10.1002/grl.50174.

_ , and _ 2014: Amplified mid-latitude planetary waves favour particular regional weather extremes. Nat. Climate Change, 4, 704-709, doi:10.1038/nclimate2271.

Sen, P. K., 1968: Estimates of the regression coefficient based on Kendall's tau. J. Amer. Stat. Assoc., 63, 1379-1389, doi:10.1080/ 01621459.1968.10480934.

Singh, D. S., D. L. Swain, J. S. Mankin, D. E. Horton, L. N. Thomas, B. Rajaratnam, and N. S. Diffenbaugh, 2016: Recent amplification of the North American winter temperature dipole. J. Geophys. Res. Atmos., 121, 9911-9928, doi:10.1002/2016JD025116.

Su, H., Z.-L. Yang, R. E. Dickinson, and J. Wei, 2014: Spring soil moisture-precipitation feedback in the Southern Great Plains:
How is it related to large-scale atmospheric conditions? Geophys. Res. Lett., 41, 1283-1289, doi:10.1002/2013GL058931.

Teng, H., G. W. Branstator, G. A. Meehl, and W. M. Washington, 2016: Projected intensification of subseasonal temperature variability and heat waves in the Great Plains. Geophys. Res. Lett., 43, 2165-2173, doi:10.1002/2015GL067574.

Thompson, D. W. J., and J. M. Wallace, 1998: The Arctic Oscillation signature in the wintertime geopotential height and temperature fields. Geophys. Res. Lett., 25, 1297-1300, doi:10.1029/ 98GL00950.

— and - 2001: Regional climate impacts of the Northern Hemisphere annular mode. Science, 293, 85-88, doi:10.1126/ science.1058958.

Trenberth, K. E., and D. J. Shea, 2005: Relationships between precipitation and surface temperature. Geophys. Res. Lett., 32, L14703, doi:10.1029/2005GL022760.

Vavrus, S., 2007: The role of terrestrial snow cover in the climate system. Climate Dyn., 29, 73-88, doi:10.1007/s00382-007-0226-0.

Vihma, T., 2014: Effects of Arctic sea ice decline on weather and climate: A review. Surv. Geophys., 35, 1175-1214, doi:10.1007/ s10712-014-9284-0.

Walsh, J. E., 2014: Intensified warming of the Arctic: Causes and impacts on middle latitudes. Global Planet. Change, 117, 5263, doi:10.1016/j.gloplacha.2014.03.003.

Wang, L., and N. Nakamura, 2015: Covariation of finite-amplitude wave activity and the zonal mean flow in the midlatitude troposphere: 1 . Theory and application to the Southern Hemisphere summer. Geophys. Res. Lett., 42, 8192-8200, doi:10.1002/ 2015GL065830.

Wetherald, R. T., and S. Manabe, 1999: Detectability of summer dryness caused by greenhouse warming. Climatic Change, $\mathbf{4 3}$, 495-511, doi:10.1023/A:1005499220385.

Willson, M. A. G., 1975: A wavenumber-frequency analysis of large-scale tropospheric motions in the extratropical Northern Hemisphere. J. Atmos. Sci., 32, 478-488, doi:10.1175/1520-0469(1975)032<0478: AWFAOL $>2.0 . \mathrm{CO} ; 2$.

Yang, J., Q. Liu, Z. Liu, L. Wu, and F. Huang, 2009: Basin mode of Indian Ocean sea surface temperature and Northern Hemisphere teleconnection. Geophys. Res. Lett., 36, L19705, doi:10.1029/2009GL039559. 